\title{
Abdominal Inflammatory Myofibroblastic Tumor: A Rare Case
}

\author{
${ }^{1}$ Fatih Tastekin, ${ }^{1}$ Mustafa Ersoy, ${ }^{2}$ Tuncer Temel, ${ }^{2}$ Safak Meric Ozgenel, ${ }^{3}$ Funda Canaz, ${ }^{1}$ Aysegül Özakyol \\ ${ }^{1}$ Department of Internal Medicine, Eskisehir Osmangazi University, Eskisehir, Turkey, ${ }^{2}$ Department of Gastroenterology, Eskisehir \\ Osmangazi University Eskisehir, Turkey, ${ }^{3}$ Department of Pathology, Eskisehir Osmangazi University, Eskisehir, Turkey
}

\begin{abstract}
An inflammatory myofibroblastic tumor, also known as inflammatory pseudotumor, is a rare neoplasm characterized by myofibroblastic spindle and inflammatory cells that cause masses in many sites of body. It is often benign, but in some cases neoplastic transformation has been reported as a result of aggressive growing. In our case, an inflammatory myofibroblastic tumor was reported by biopsy of a $25 \times 15 \mathrm{~cm}$ abdominal mass.

Keywords: Abdominal mass, Inflammatory myofibroblastic tumor, Inflammatory pseudotumor.

How to cite this article: Tastekin F, Ersoy M, Temel T, Ozgenel SM, Canaz F, Özakyol A. Abdominal Inflammatory Myofibroblastic Tumor: A Rare Case. Euroasian J Hepato-Gastroenterol 2016;6(2):183-185.

Source of support: Nil

Conflict of interest: None

Copyright and License information: Copyright (c) 2016; Jaypee Brothers Medical Publishers (P) Ltd. This work is licensed under a Creative Commons Attribution 3.0 Unported License. To view a copy of this license, visit http://creativecommons.org/licenses/by/3.0/
\end{abstract}

\section{INTRODUCTION}

Inflammatory myofibroblastic tumor is a disorder that cause masses in many sites of body and that is not still to be proven whether it is an inflammatory course or a true neoplasm. ${ }^{1}$ It is often benign, but in some cases neoplastic transformation has been reported as a result of aggressive growing. Other names of this entity in the literature are inflammatory pseudotumor, pseudosarcomatous myofibroblastic proliferation, pseudosarcomatous myofibroblastic tumor, pseudosarcomatous reactive response, atypical myofibroblastic tumor, atypical fibromixoid tumor, plasma cell granuloma, and bladder nodular fasciitis.

\section{CASE REPORT}

A 60-year-old man has been examined due to complaints like oral intake disorder and weight loss, and an abdominal mass was detected. He was referred to our department (Eskişehir Osmangazi University, Medical Faculty Hospital, Gastroenterology Clinic) by the suspicion of cancer derived liver. A $25 \times 15 \times 24 \mathrm{~cm}$ mass, which has an undistinguishable tissue origin, was observed on dynamic magnetic resonance imaging (MRI) (Figs 1 to 3). The mass caused compression on stomach and the other tissues within the abdomen. A peripheral parenteral nutrition was started because the stomach collapsed. We performed an ultrasound-guided biopsy and determined a mesenchymal spindle cell tumor (Fig. 4). So, a curative or a palliative surgery was decided by consultation of medical oncology and general surgery department. The mass could not be excised due to invasion during the operation. A jejunostomy has been performed for enteral nutrition, and the patient was referred to medical oncology for further therapy.

\section{DISCUSSION}

An inflammatory myofibroblastic tumor is often referred as an inflammatory pseudotumor. It is a rare neoplasm characterized by myofibroblastic spindle and inflammatory cells and is particularly located in soft tissues. It is often benign, but in some cases, neoplastic transformation has been reported as a result of aggressive growing. ${ }^{2}$ Infection, trauma, irradiation, and autoimmune ground are considered in disorder's etiology, but etiology is still not clear. ${ }^{3}$ Symptoms are varied based on involved body part. However, abdominal discomfort, dyspepsia, oral intake disorder, weight loss, and mass with palpation may be seen in cases with abdominal involvement, such as the case in our patient. When we examine patterns macroscopically, they are benign, restricted, and not encapsulated; also nodular and diffuse growing patterns are

Address reprint requests to: Safak Meric Ozgenel, Assistant Professor, Department of Gastroenterology, Osmangazi University Eskisehir, Turkey, Phone: +902222392979, e-mail: mozgenel@ogu.edu.tr 


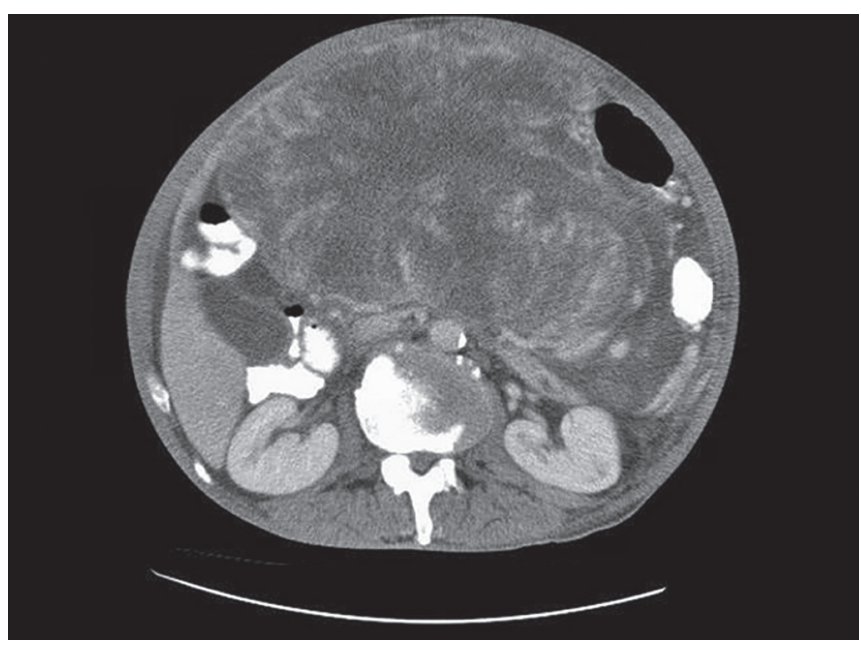

Fig. 1: Inflammatory mass by MRI

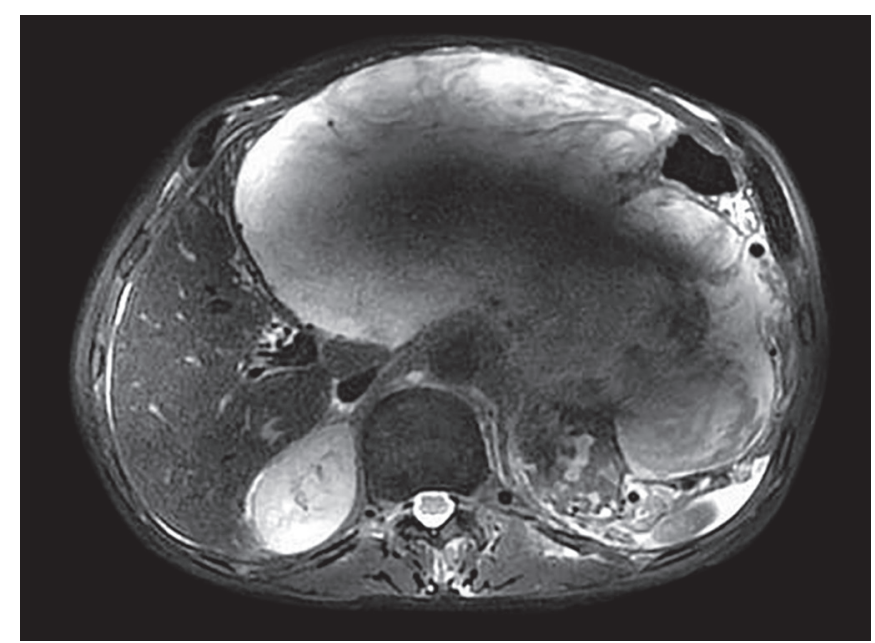

Fig. 3: Inflammatory mass by MRI

observed. If we investigate it microscopically, spindle cell proliferation and mixed types of inflammatory cells are there in collagenated loose stroma. Immunohistochemical investigation contributes to confirmation of diagnosis. Vimentin, Smooth Muscle Actin (SMA), and Cluster of differentiation 68 (CD68) are positive. In addition, anaplastic lymphoma kinase (ALK) reveals cytoplasmic staining in myofibroblastic cells. ${ }^{4}$ Ultrasonography, especially computed tomography and MRI, is necessary for diagnosis. Most common involved body part is lung, but involvement of larynx, spleen, breast, bladder, central nervous system, pancreas, orbita, mesentery, prostate, salivary glands, testes, and skin have been reported., ${ }^{5,6}$ First choice of treatment, if available, is complete resection in most patients; if not, radiotherapy and steroid use is recommended. The other treatment choices are immunomodulation (cyclosporine A), chemotherapy (methotrexate, azatiopurine, chlorambucil, cyclophosphamide, iphosphamide, vincristin, dactinomycin), and antimetabolite regimen. ${ }^{2}$ Early diagnosis and total excision are significant in good prognosis. Although pathogenic organisms are reported

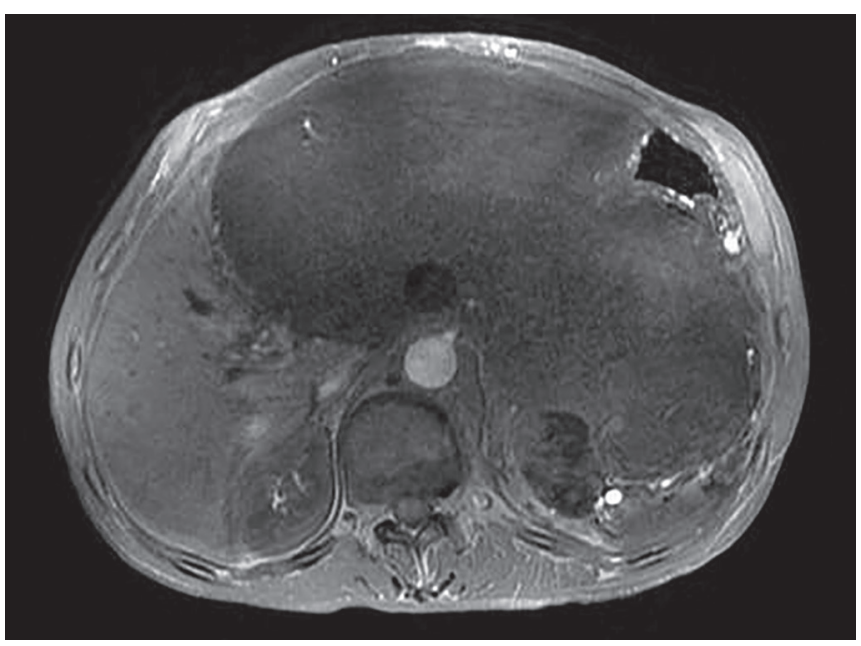

Fig. 2: Inflammatory mass by MRI

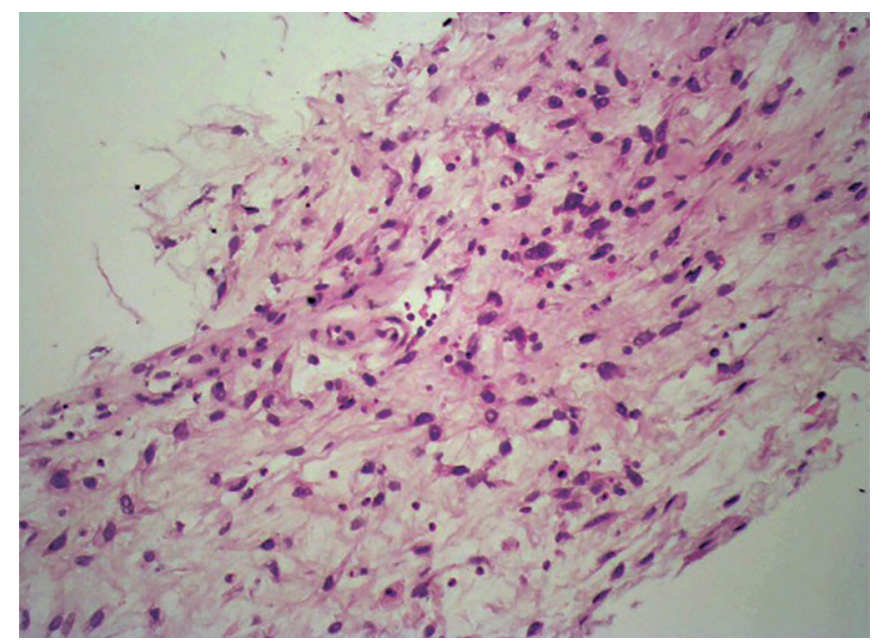

Fig. 4: Histopathological assessment of inflammatory mass

in most inflammatory myofibroblastic tumor cases, resection should be always considered due to presence of malignant transformation in some cases.

\section{CONCLUSION}

We evaluated a rare inflammatory myofibroblastic tumor in our case. The tumor was large and had an interesting pathogenesis. Therefore, we decided to report it.

\section{ACKNOWLEDGMENTS}

The work conforms to the provisions of the Declaration of Helsinki, and a written consent of the subject has been acknowledged.

\section{REFERENCES}

1. Pungpapong S, Geiger XJ, Raimondo M. Inflammatory myofibroblastic tumor presenting as a pancreatic mass: a case report and review of the literature. J Pancreas 2004 Sep;5(5):360-367.

2. Cerrahoğlu Şirin T, Çelebisoy N, Gökçay F. Steroid responsive inflammatory myofibroblastic tumor with central nervous 
system involvement: the case report. J Neurological Sci 2013 Jan;30(1):219-224.

3. Tira Ü, Kuru S, Doru Ö. A. Myofıbroblastic tumor located in mesenterium. Nobel Med 2011;7(2):101-102.

4. Bedir R, Şehitoğlu İ, Uzun H, Yurdakul C. Inflammatory pseudotumor of the epididymis: a case report and review of the literature. Turkish J Urol 2013 Dec;39(4):281-284.
5. Çetin A, Akyıldız Ĭğdem A, Er M, Ekici Y, Erdoğan N. Inflammatory myofibroblastic tumor of the liver (Case Report). Türkiye Ekopatoloji Dergisi 2005;11(2):75-79.

6. Eliyatkin N, Günlüsoy B, Olgun AG, Alikanoğlu AS, Postaci H. Inflammatory myofibroblastic tumor of the urinary bladder: differential diagnosis. Turkiye Klinikleri J Med Sci 2010 Dec;30(6):2067-2071. 